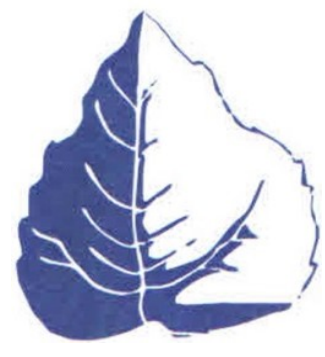

УДК 332.84

\section{ЭКОЛОГИЯ (ПО ОТРАСЛЯМ) ECOLOGY (ITS BRUNCHES)}

Экологическое зонирование урбанизированных территорий

https://doi.org/10.23947/2413-1474-2021-5-4-52-58

Овчинникова Н. Г., Водолазская Т. С.

Донской государственный технический университет (Ростов-на-Дону, Российская Федерация)

Рассмотрена необходимость экологического зонирования для решения экологических проблем, возникающих в процессе урбанизации городских территорий и препятствующих их устойчивому развитию. Проанализированы также виды экологического зонирования территории.

Ключевые слова: зонирование территории, экологическое зонирование, устойчивое развитие, городские территории.

Для цитирования: Овчинникова, Н. Г. Экологическое зонирование урбанизированных территорий / Н. Г. Овчинникова, Т. С. Водолазская // Экономика и экология территориальных образований. — 2021. — Т. 5, № 4. — С. 52-58. https://doi.org/10.23947/2413-1474-2021-5-4-52$\underline{58}$

\title{
Ecological zoning of urbanized territories
}

Ovchinnikova N. G., Vodolazskaya T. S.

Don State Technical University (Rostov-on-Don, Russian Federation)

In the article, the authors consider the need for ecological zoning to solve environmental problems that arise during the urbanization of urban areas and hinder the sustainable development of urban areas. As well as types of ecological zoning of the territory.

Keywords: zoning of the territory, ecological zoning, sustainable development, urban areas.

For citation: N. G. Ovchinnikova, T. S. Vodolazskaya. Ecological zoning of urbanized territories. Economy and ecology of territorial formations, 2021, vol. 5, no 4, pp. 52-58. https://doi.org/10.23947/2413-1474-2021-5-4-52-58

Введение. В современном мире большое внимание уделяется вопросам устойчивого развития во всех сферах жизни нашего общества. Устойчивое развитие - развитие общества, при котором условия жизни людей улучшаются, а воздействие на окружающую среду остаётся в пределах исчерпания её ресурсов. Иными словами, концепция устойчивого развития предполагает гармоничные и бесконфликтные отношения природы и общества. Цели данной кон- 
цепции разнонаправленные. При этом значительную роль играет устойчивое развитие территорий городов. Уверенно можно сказать, что устойчивое развитие городов рассматривается как ключевой фактор развития современной экономики. Под устойчивым развитием городских территорий понимается соблюдение баланса между экологическими, экономическими и социальными факторами развития общества. Так, одна из 17 целей устойчивого развития в Российской Федерации, а именно цель № 11 «Обеспечение открытости, безопасности, жизнестойкости и экологической устойчивости городов и населенных пунктов», напрямую связана с развитием городов. С жизнью в городе связаны и другие цели, что ещё раз подчёркивает важность проблемы устойчивого развития городской среды.

Основная часть. Необходимым условием устойчивого развития является рациональность организации территории, то есть в процессе ее обустройства и развития инфраструктуры ущерб, наносимый окружающей среде, должен максимально уменьшаться. Рациональность организации территории предполагает грамотное ведение градостроительной деятельности [1-6]. К сожалению, современный уровень ведения градостроительной деятельности носит нерациональный характер использования потенциала городских территорий при планировании и разработке генеральных планов их развития. Слабая изученность хозяйственной освоенности территории, состояния объектов природно-экологического каркаса и его неполного представления в наглядном виде приводи00т к тому, что разработка генеральных планов подобных территорий ведётся некорректно [7]. А ведь именно природно-экологический каркас города, представленный городскими парками, лесопарками и другими озелененными территориями большой площади, озерами и водохранилищами с прибрежными территориями (планировочные центры) и соединяющими их линейными (ленточными) парками, долинами рек и ручьев, оврагами (природные планировочные оси), обеспечивает устойчивость и взаимосвязанность природных элементов в урбанизированной среде - выполняет важную экологическую функцию. Кроме того, быстрый рост городских территорий по площади приводит к тому, что всё больше природных экосистем подвергается отрицательному воздействию хозяйственной деятельности, что в итоге ведёт к полному уничтожению природных объектов, а это нарушает экологическое равновесие [8-13]. В процессе урбанизации городских территорий антропогенной нагрузке поддаются практически все компоненты природной среды. В связи с этим возникает острая необходимость экологического зонирования.

Под зонированием в широком смысле этого термина понимается деление определенной территории на части (зоны) и определение для каждой из них особого режима [14-15]. Для каждой из зон предусмотрены свои виды использования, что напрямую зависит от выполняемых ею функций (рис. 1). 


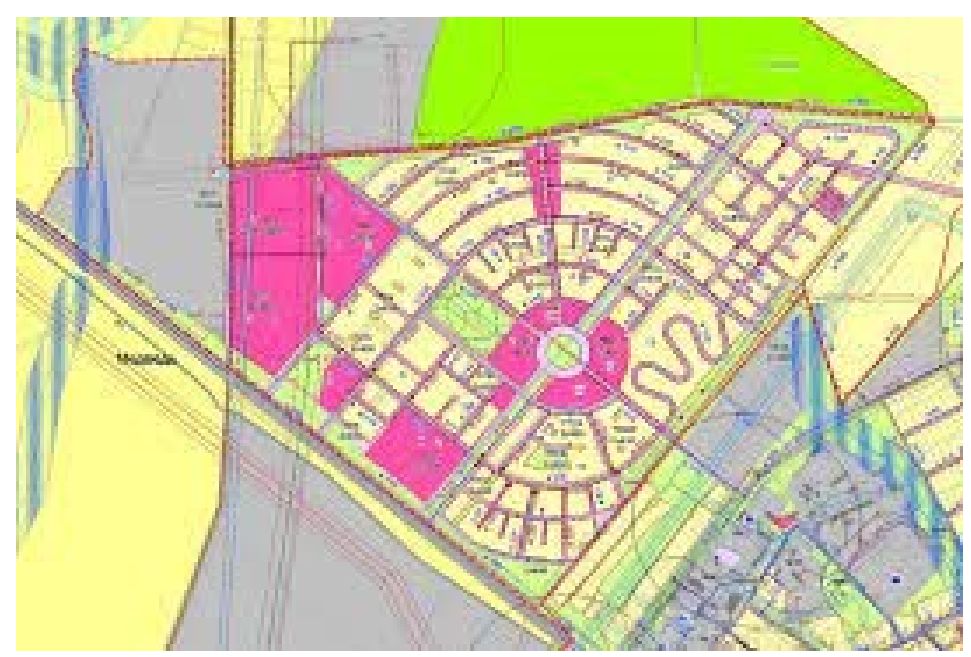

Рис. 1. Проект планировки территории

Экологическое же зонирование подразумевает интеграцию различных видов зонирования (рис. 2).

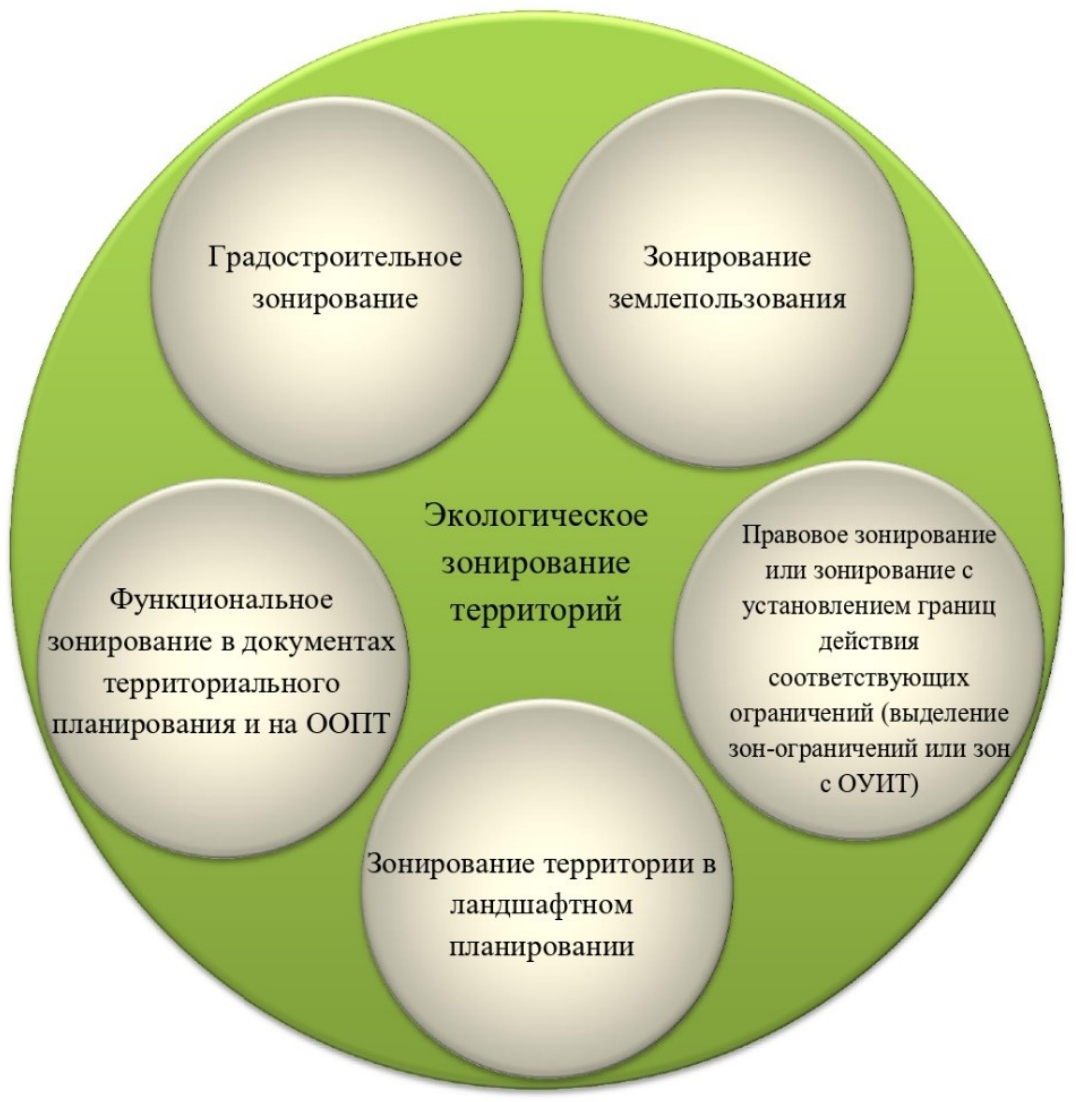

Рис. 2. Состав экологического зонирования территорий

При экологическом зонировании среды исследуются физико-географические условия природной среды, которые представлены на рис. 3. 


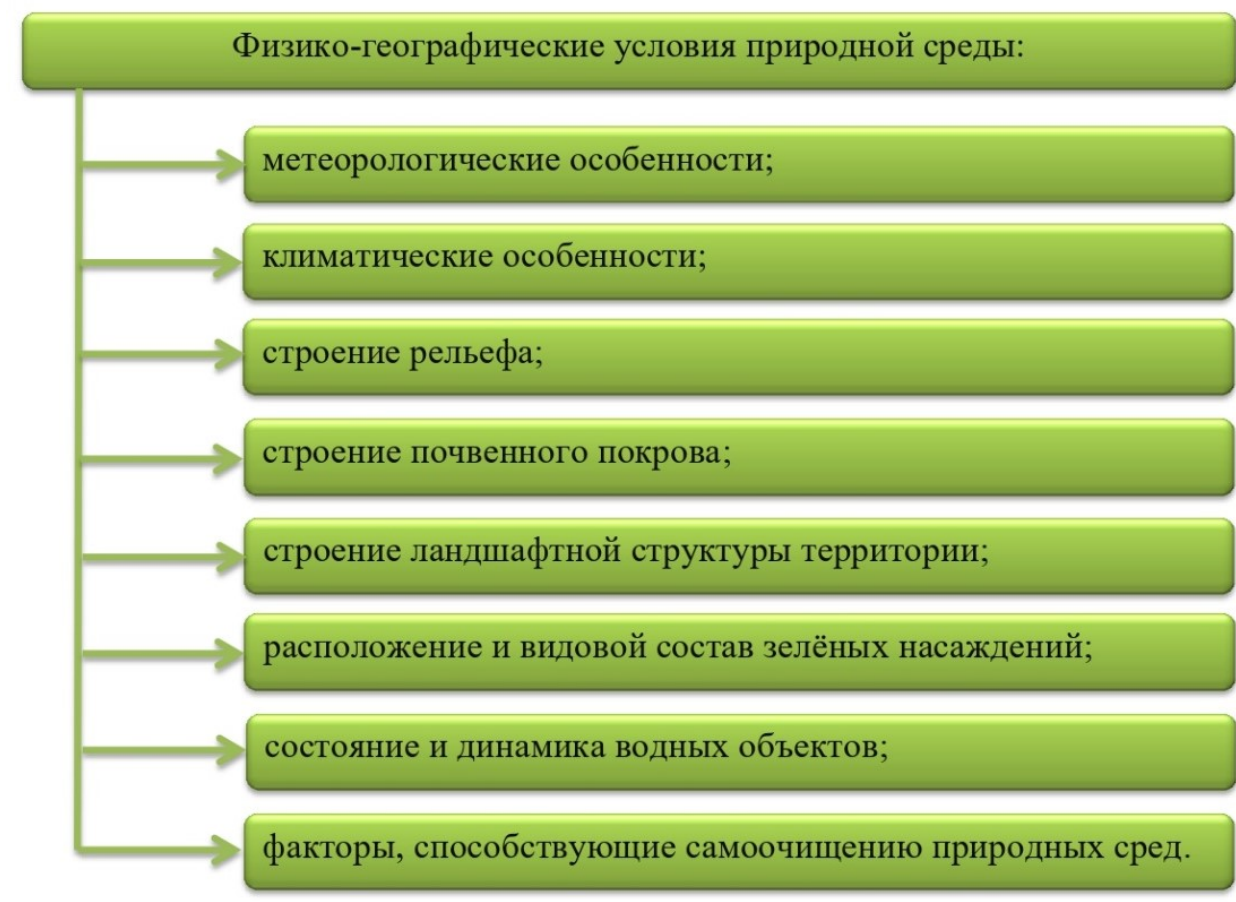

Рис. 3. Физико-географические условия природной среды

Виды экологического зонирования территории определяются в зависимости от критерия зонирования и от степени влияния техногенных и природных объектов на состояние земель.

Методы, которые используются при определении показателей в зависимости от критерия экологического зонирования, с течением времени значительно усовершенствовались. Так, ранее использовали метод анализа химических проб той или иной местности. Однако у него есть свои минусы. Это трудоёмкость, дискретность выбора пробы и территории, что влияет на достоверность результатов.

Потребность в экологическом зонировании территорий с экологическими проблемами возникает из-за недостаточной методической проработки данного вопроса. Процесс экологического зонирования должен быть непрерывным. Пример экологического зонирования можно увидеть на рис. 4. 


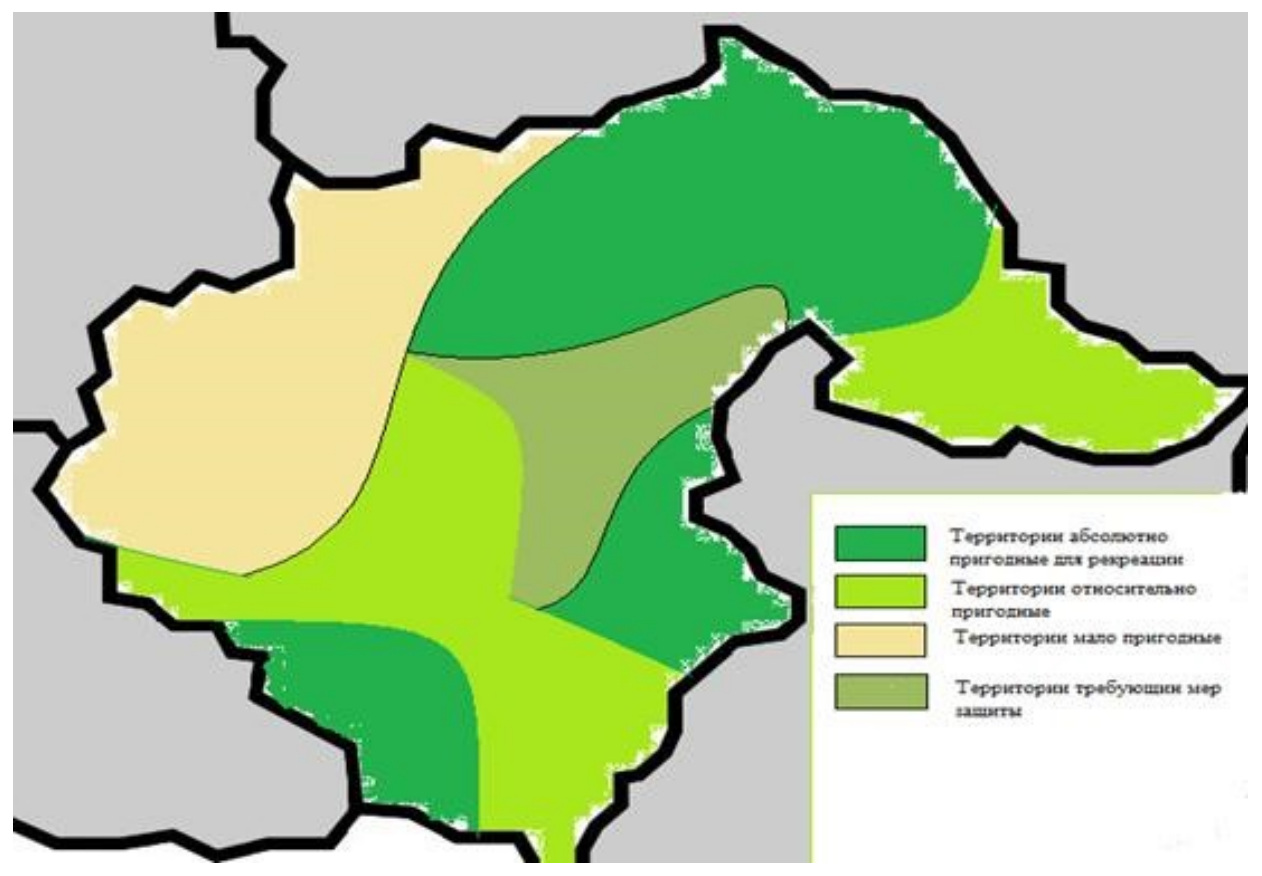

Рис. 4. Пример экологического зонирования

Заключение. Содержание процедуры зонирования наиболее четко определено градостроительным законодательством. Градостроительное зонирование является правовым мероприятием, чего нельзя, к сожалению, сказать об экологическом зонировании. Одной из основных проблем экологического зонирования территории является недостаточная правовая организация. Нет целостной сформированной системы природоохранных мер.

\section{Библиографический список}

1. Медведков, Д. А. Комплексное и устойчивое развитие застроенной территории: опыт, проблемы и пути их решения / Д. А. Медведков, Н. Г. Овчинникова // Организационноэкономические проблемы регионального развития в современных условиях : материалы научно-практической конференции молодых ученых, аспирантов и студентов. - Симферополь, 2018. - С. 204-206.

2. Овчинникова, Н. Г. Социо-эколого-экономическое моделирование процессов управления земельными ресурсами в сфере сельскохозяйственного производства / Н. Г. Овчинникова // Terra Economicus. - 2011. - T. 9, № 3-2. - C. 89-91.

3. Овчинникова, Н. Г. Разработка и принятие проектных решений по организации рационального использования земельных ресурсов / Н. Г. Овчинникова // Известия Ростовского государственного строительного университета. — 2011. — № 15. — С. 225-230.

4. Овчинникова, Н. Г. Оценка производственного потенциала сельскохозяйственных предприятий / Н. Г. Овчинникова, С. Н. Гончарова // Науковедение. - 2012. — № 3 (12). С. 112 .

5. Овчинникова, Н. Г. Ответственность кадастрового инженера в сфере земельно-имущественных отношений / Н. Г. Овчинникова, Е. С. Шумкова // Экономика и экология территориальных образований. - 2015. - № 3. - С. 36-39.

6. Овчинникова, Н. Г. Учетно-регистрационный процесс в системе управления земельными ресурсами / Н. Г. Овчинникова, Е. С. Шумкова // Экономика и экология территориальных образований. - 2016. - № 2. - С. 125-129. 
7. Овчинникова, Н. Г. Государственный кадастровый учет как инструмент информационного обеспечения системы управления земельными ресурсами и развития земельного рынка / Н. Г. Овчинникова, А. И. Щиренко // Экономика и экология территориальных образований. - 2016. - № 2. - С. 67-71.

8. Овчинникова, Н. Г. Организация рационального использования земельных ресурсов при территориальном планировании муниципальных образований / Н. Г. Овчинникова, В. В. Шмакова // Экономика и экология территориальных образований. — 2017. — № 4. C. $80-90$.

9. Русских, А. В. Значимость документов территориального планирования муниципального образования для ведения ЕГРН / А. В. Русских, Н. Г. Овчинникова // Научные труды КубГТУ. - 2017. - № 4. - С. 285-289.

10. Алиева, Н. В. Функции управления земельными ресурсами в решении вопросов развития территорий субъекта Российской Федерации / Н. В. Алиева, Н. Г. Овчинникова // Вестник Южно-Российского государственного технического университета (Новочеркасского политехнического института). Серия: Социально-экономические науки. - 2017. — № 3. C. $79-83$.

11. Ovchinnikova N.G. Analysis of territorial planning and prospects for further development of urban districts and settlements in Rostov region // MATEC Web of Conferences. 2017. P. 01004.

12. Ovchinnikova N., Vodolazskaya T. Challenges and perspectives for rural development B сборнике: E3S Web of Conferences. XIV International Scientific and Practical Conference "State and Prospects for the Development of Agribusiness - Interagromash 2021”. Rostov-on-Don, 2021. P. 06007.

13. Ovchinnikova N., Aliyeva N., Petrova I. Principles and methodological approaches to efficient use of land. В сборнике: E3S Web of Conferences. XIV International Scientific and Practical Conference "State and Prospects for the Development of Agribusiness -Interagromash 2021". Rostov-on-Don, 2021. P. 06008.

14. Ovchinnikova N. Analysis of sustainable development of rural areas in Russia: results, challenges and solutions B сборнике: E3S Web of Conferences. 8. "Innovative Technologies in Science and Education, ITSE 2020" 2020. P. 14002.

15. Ovchinnikova N., Batranyuk M., Zhidkova E., Lazebnaya Y., Timofeeva V. Main areas of land use in municipal entity. В сборнике: E3S Web of Conferences. 8. "Innovative Technologies in Science and Education, ITSE 2020" 2020. P. 09004.

\section{Об авторах:}

Овчинникова Наталья Геннадьевна, доцент кафедры «Экономика природопользования и кадастра» Донского государственного технического университета (344003, РФ, г. Ростов-на-Дону, пл. Гагарина, 1), кандидат экономических наук, доцент, donong160875@yandex.ru

Водолазская Татьяна Сергеевна, магистрант кафедры «Экономика природопользования и кадастра» Донского государственного технического университета (344003, РФ, г. Ростов-на-Дону, пл. Гагарина, 1), 1chinaski1@gmail.com 


\section{Authors:}

Ovchinnikova, Natalya G., associate professor, the department of «Economics of Nature Management and Cadastre», Don State Technical University, (1, Gagarin Square, Rostov-on-Don, 344003, RF), associate professor, Ph.D. in Economics, donong160875@yandex.ru

Vodolazskaya, Tatiana S., master degree student, the Department of «Environmental Economics and cadaster» Don State Technical University, (1, Gagarin Square, Rostov-on-Don, 344003, $\mathrm{RF})$ 